\title{
Synthesis, Characterization and Antibacterial and Antifungal Studies of Schiff base Polymers derived from Methylene bis Cinnamaldehyde
}

\author{
Moina Akhtar Mughal ${ }^{1}$, Akhtar Hussain Mughal ${ }^{2}$, Zeenat M. Ali ${ }^{3}$, \\ Ghulam Zuhra Memon ${ }^{1}$, Mohammad Yar Khuhawar ${ }^{4}$, Hussain Saleem ${ }^{5}$ \\ ${ }^{1}$ Dr. Mumtaz Ali Kazi Institute of Chemistry, University of Sindh, Jamshoro, Pakistan \\ ${ }^{2}$ Institute of Physics, University of Sindh, Jamshoro, Pakistan \\ ${ }^{3}$ Mehran University of Engineering \& Technology, Jamshoro, Sindh, Pakistan \\ ${ }^{4}$ Institute of Advanced Research Studies in Chemical Sciences, University of Sindh, Jamshoro, Pakistan \\ ${ }^{5}$ Department of Computer Science, University of Karachi, Karachi, Pakistan
}

\begin{abstract}
The present study explores the synthesis and characterization of all the compounds via Carbon-Hydrogen-Nitrogen (C.H.N.) analysis with infrared, ultraviolet spectroscopy. Antibacterial and Antifungal studies of these compounds against different antibacterial and antifungal microorganisms gave important findings. Six new Schiff base polymers Poly 4,4-methylene bis(cinnamaldehyde) 1,2-diiminopropane (PMbCPn), Poly 4,4-methylene bis(cinnamaldehyde) 1,3-diiminopropane (PMbCPR), Poly 4,4-methylene bis(cinnamaldehyde) ethylenediimine (PMbCen), Poly 4,4-methylene bis(cinnamaldehyde) 1,2-phenylenediimine (PMbPCPh), Poly 4,4-methylene bis(cinnamaldehyde) Urea (PMbCU), Poly 4,4-methylene bis(cinnamaldehyde) Semicarbazide (PMbCSc), and Poly 4,4-methylene bis(cinnamaldehyde) Thiosemicarbazide (PMbCTSc), were prepared by polycondensing these polymers with methylene bis cinnamaldehyde by a general method. The monomer and Schiff base polymers presented considerable antimicrobial results.
\end{abstract}

Keywords -Antibacterial, Antifungal, Antimicrobial, Characterization, Polymers, Synthesis

\section{INTRODUCTION}

Distinctive and apparent attention of scientists worldwide have been focused on antibacterial and antifungal studies of polymers. Polyethylene glycol methyl ether methacrylate and 4-vinyl pyridine copolymers displayed substantial antibacterial properties [14]. Antibacterial polymers have potential to be used in pharmaceuticals and coats of embedding devices [2]. Iron III, Cromium III, Mangnese III, and Tie III Chelate polymers by means of a polymeric Schiff base ligand, derived from 1,3-propylenediamine and 4,4 bis(salicylaldehyde)azo, were synthesized and characterized spectroscopically and thermally. Antimicrobial studies of the prepared compounds indicated promising inhibitory effects against microorganisms [6]. Different Schiff base polymers were prepared and considered via FTIR, UV/Vis and HNMR [3], [7]. Renowned Scientists worldwide testified the polymeric Schiff bases as catenation ligands, wherever the widespread studies of these coordinating polymers is considered [1], [4], [5], [8], [10], [11], [12], [13].

\section{EXPERIMENTAL WORK}

$\mathrm{NH}_{2} \mathrm{CONH}_{2}$, 1,3-diaminopropane, 1,2-diaminopropane, diaminoethane, 1,2-phenylenediamine, acetic acid, 1,3,5-trioxane, n-hexane, semicarbazide, thiosemicarbazide. All the microorganisms S.Aureus, M.Flavus, B.Cirroflgellosus, S.Flexneri, E.Coli, C.Albicans, A.Niger and A.Flavus, were provided by Doctor M. Kumar, Eye Hospital Pathology lab, Hyderabad, and Institute of Microbiology. Experimental work was accomplished at Doctor Mumtaz Ali Kazi Institute of Chemistry, University of Sindh, Jamshoro using well diffusion method.

\section{SYNTHESIS OF MONOMER}

Cinnamaldehyde $(19.39 \mathrm{~mL})$ was added into $\mathrm{CH}_{3} \mathrm{COOH}(12.49 \mathrm{~mL})$ within the temperature range $89.9^{\circ} \mathrm{C}$ to $94.9^{\circ} \mathrm{C}$ in an inert atmosphere. Trioxane $(1.75 \mathrm{gm})$ was dissolved into $0.125 \mathrm{~mL}$ of $\mathrm{H}_{2} \mathrm{SO}_{4}$ and $0.625 \mathrm{~mL} \mathrm{CH}_{3} \mathrm{COOH}$ mixture and was poured into the cinnamaldehyde, acetic acid mixture, drop by drop with constant stirring. The reaction mixture was stirred constantly for twenty four hours. The resulting mixture was left for precipitation for further 12 hours after addition of one liter of cold distilled water. The recovered product was washed with ethyl alcohol and di-ethyl ether and was kept in oven for drying at the temperature of $100^{\circ} \mathrm{C}$. The melting point recorded was greater than $300^{\circ} \mathrm{C}$. 


\section{SYNTHESIS OF SCHIFF BASE POLYMERS}

Bis cinnamaldehyde (3gm) was dissoluted in $(45 \mathrm{~mL})$ DMSO and into this, the addition of different diamines like 1,2-diaminopropane $(0.5 \mathrm{~mL}), 1,3$-diaminppropane $(0.5 \mathrm{~mL})$, diaminoethane $(0.7 \mathrm{~mL}), \mathrm{NH}_{2} \mathrm{CONH}_{2}$ $(0.59 \mathrm{gm}), 1,2$-phenylenediamine $(0.4 \mathrm{~mL})$, semicarbazide $(0.34 \mathrm{gm})$ and thio semicarbazide $(0.45 \mathrm{gm})$ was carried out with constant stirring the contents, and then was refluxed for 24 hours. The volume of the contents was then reduced via distillation and then $(40 \mathrm{~mL})$ ethyl alcohol was added. Fine product formed was washed, filtered and recrystallized from $\mathrm{CHCL}_{3} /$ normal hexane. All the polymeric Schiff bases were melted above $350^{\circ} \mathrm{C}$.

\section{Characterization}

The C.H.N. analysis was conducted at Carlo Elba Devon, United Kingdom. The FTIR studies were conducted on 330 FTIR (Thermo Nicolet Electro Corporation, America) in the range $4000-600 \mathrm{~cm}^{-1}$. An ultraviolet visible spectroscopic study was conducted in DMSO on a double beam spectrophotometer (Hitachi-220, Japan). Silica cuvettes one centimeter were used. The antibacterial and antifungal studies were carried out by using tetracycline and miconazole as antibacterial and antifungal as standard drugs. The strains were applied with the help of platinum wire loop. The concentration of samples under investigation suggested was $1 \mathrm{mg} / \mathrm{mL}$ in dimethylformamide. Inoculation of cultures of the samples were carried out before pouring into petri plates. The $24 \mathrm{~mm}$ in diameter wells were dug in the media with the help of cork borer. The sample solutions of monomer and Schiff base polymers were individually poured into the wells by using a micro pipette, the other wells were poured with Dimethylforamide and reference Tetracycline and Miconazole, offering as $+v e$ and $-v e$ controls. The petri plates were kept in oven at the temperature of $37^{\circ} \mathrm{C}$ for 24 hours. The zones of inhibition were measured with a measuring scale (ruler) in mm [9], [15], [16].

\section{RESULTS AND DISCUSSION}

Methylene bis Cinnamaldehyde was synthesized by a general method. The precipitates were obtained in good yield. The C.H.N. analysis of the synthesized compounds provided results that were in good agreement with the calculated values as shown in Table-1.

Table-1: C.H.N. Availability Analysis of Monomer and Polymers

\begin{tabular}{|c|c|c|c|c|c|c|c|}
\hline \multirow{2}{*}{ Compound } & \multirow{2}{*}{$\begin{array}{c}\text { Melting } \\
\text { Point }\left({ }^{\circ} \mathbf{C}\right)\end{array}$} & \multicolumn{2}{|c|}{ Carbon (C) } & \multicolumn{2}{|c|}{ Hydrogen (H) } & \multicolumn{2}{|c|}{ Nitrogen (N) } \\
\hline & & Calculated & Found & Calculated & Found & Calculated & Found \\
\hline MbC & $>300$ & $83.0 \%$ & $82 \%$ & $5.8 \%$ & $6.0 \%$ & - & - \\
\hline PMbCPn & $>350$ & $83.9 \%$ & $84 \%$ & $6.9 \%$ & $7.0 \%$ & $9.0 \%$ & $6.0 \%$ \\
\hline PMbCPR & $>350$ & $84.0 \%$ & $84 \%$ & $6.9 \%$ & $7.0 \%$ & $9.0 \%$ & $7.0 \%$ \\
\hline PMbCen & $>350$ & $83.9 \%$ & $84 \%$ & $7.0 \%$ & $6.4 \%$ & $9.3 \%$ & $9.0 \%$ \\
\hline PMbCU & $>350$ & $79.8 \%$ & $80 \%$ & $5.4 \%$ & $5.2 \%$ & $9.3 \%$ & $9.0 \%$ \\
\hline PMbCSc & $>350$ & $79.9 \%$ & $80 \%$ & $5.4 \%$ & $5.0 \%$ & $9.39 \%$ & $9.0 \%$ \\
\hline PMbCTSc & $>350$ & $73.0 \%$ & $74 \%$ & $5.2 \%$ & $5.0 \%$ & $13.0 \%$ & $12.0 \%$ \\
\hline
\end{tabular}


The monomer when poly condensed with different diamines presented six Schiff base polymers. The structural schematic diagrams of monomer and polymers are shown in Figure-1(a) and Figure-1(b) respectively.<smiles>O=CC=Cc1ccc(Cc2ccc(C=CC=O)cc2)cc1</smiles>

(a) Monomer

СHO

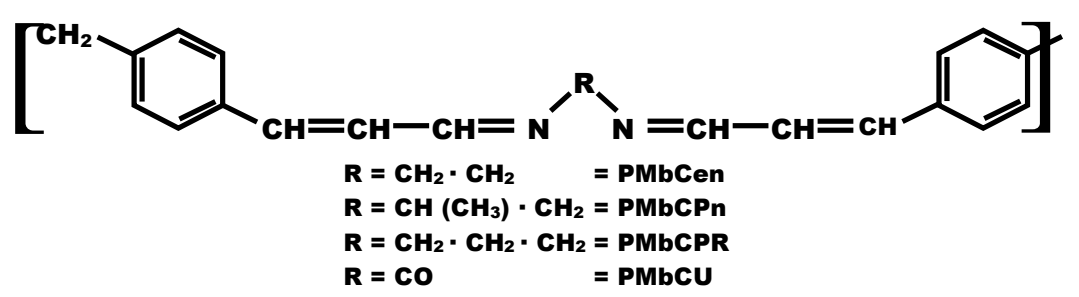

(b) Schiff base Polymers

Table-2: Solubility of Monomer and Polymers in Organic Solvents

\begin{tabular}{|l|c|c|c|c|c|c|c|}
\hline Compound & $\mathbf{H}_{2} \mathrm{O}$ & Etoh & CHCL3 & THF & DMSO & Acetone & Butanol \\
\hline MbC & - & - & + & + & + & + & + \\
\hline PMbCPn & - & \pm & \pm & + & - & - & - \\
\hline PMbCPR & - & - & - & - & - & \pm & - \\
\hline PMbCen & - & - & - & + & + & - & - \\
\hline PMbCU & \pm & + & - & - & + & - & - \\
\hline PMbCSc & - & - & \pm & - & + & - & - \\
\hline PMbCTSc
\end{tabular}

Among the synthesized compounds the parent compound showed better solubility as compared to its polymers. The results are summarized in Table-2. The FTIR studies displayed visible differences between the parent monomer and polymers. The parent compound indicated absorption bands around 1700 and $1683 \mathrm{~cm}^{-1}$. Similar bands were not visible in Schiff base polymers as these bands disappear or became slightly visible after poly condensation. A 20 to $24 \mathrm{~cm}^{-1}$ shift towards lower frequencies in Schiff base polymers was observed as compared to the parent compound as shown graphically in Figure-2(a) for MbC, Figure-2(b) for PMbCen, and Figure-2(c) for PMbCPR respectively for Transmittance in percentage. 


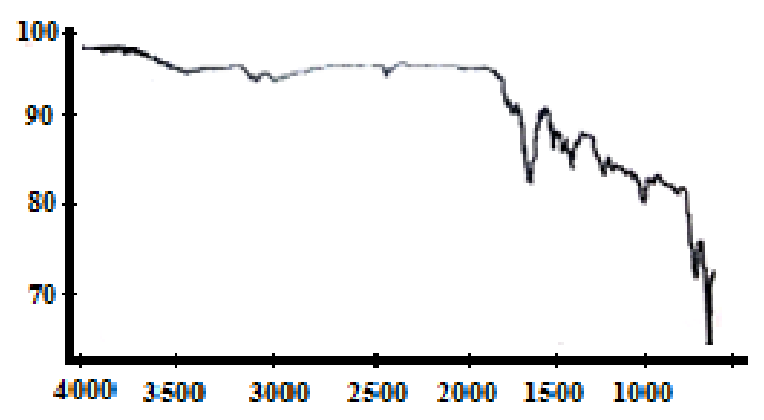

Figure-2(a): Transmittance percentage for Monomer MbC

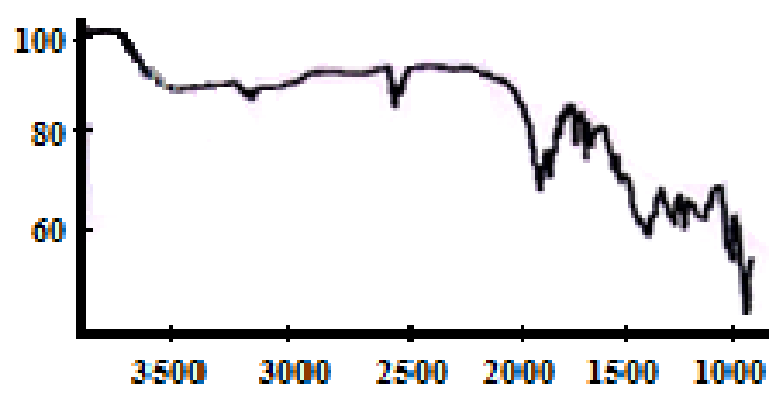

Figure-2(b): Transmittance percentage for Polymer PMbCen

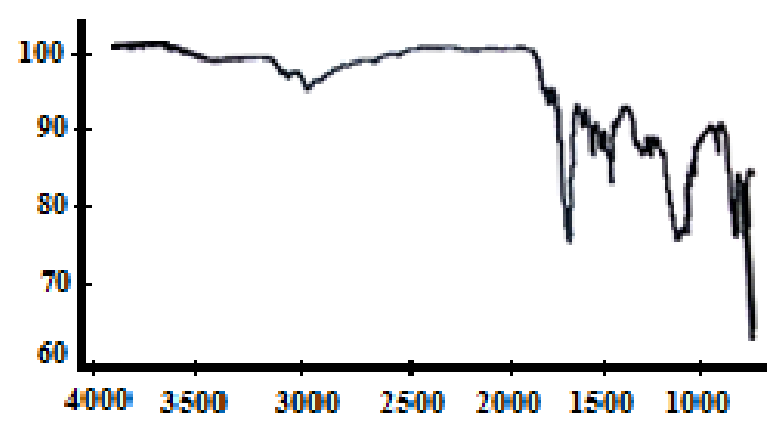

Figure-2(c): Transmittance percentage for Polymer PMbCPR

The Azomethine ${ }^{v} \mathrm{C}=O$ within 1625 to $1665 \mathrm{~cm}^{-1}$ was visible in Schiff base polymers, as this band appears after polymerization. The HNMR studies established the structure of the prepared compounds. A very clear and sharp peak of $\mathrm{CHO}$ group was seen in monomer at $\delta 8.79$ which was shown as a weak-band in polymers. The Ultraviolet studies were conducted in DMSO and Tetrahydrofuran (THF). The parent compound presented bands at $262 \mathrm{~nm}$ and $338 \mathrm{~nm}$ indicating $\pi$ to $\pi^{*}$ conversions in benzoid rings and $\pi$ to $\pi^{*}$ alternate $C=O$ groups. The Schiff base polymers presented more than two bands as shown in Figure-3 where absorbance is also shown. 


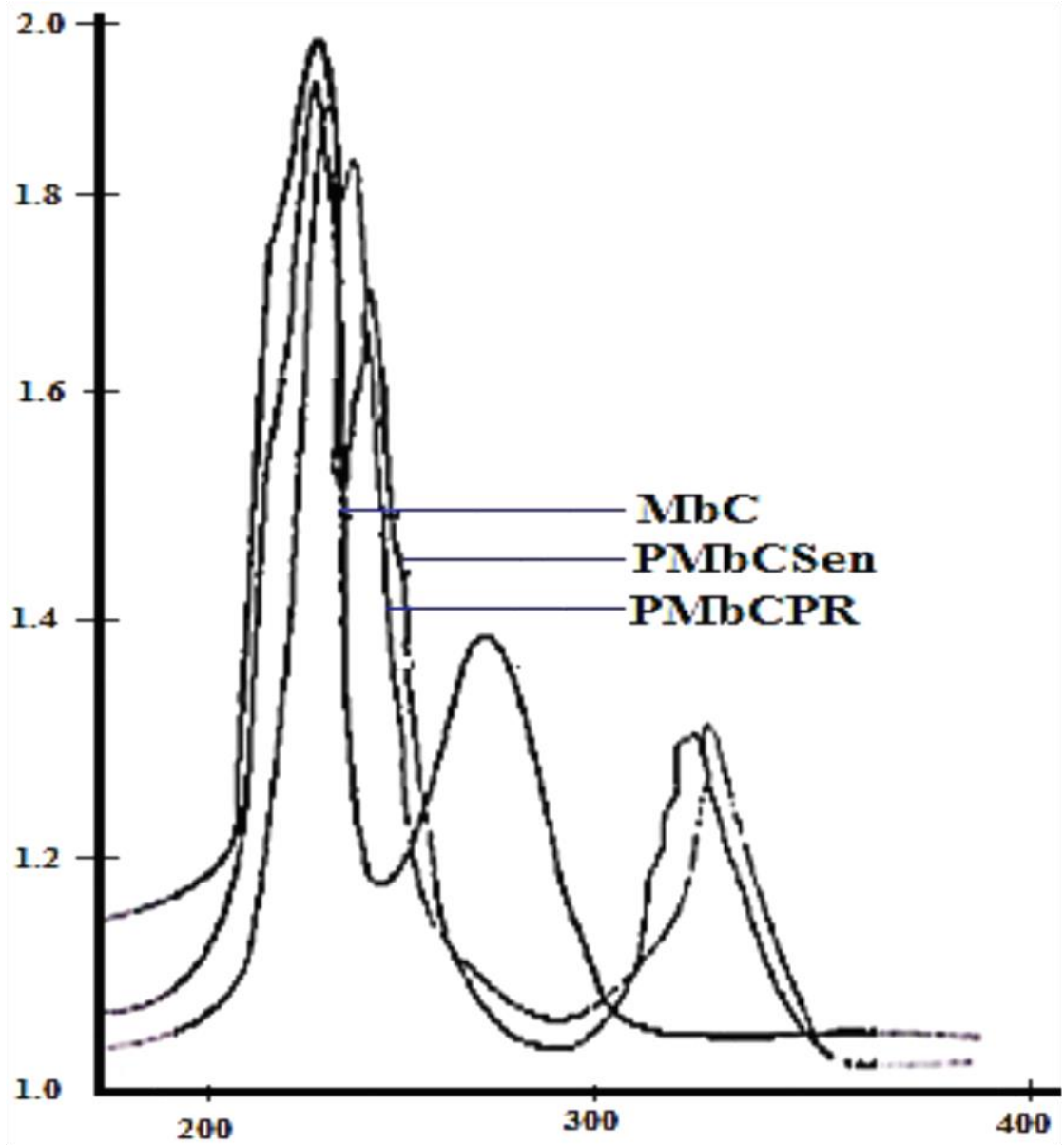

Figure-3: Absorbance

A significant bathochromic shift of 15-20nm was observed in Schiff base polymers as compared to monomer which is explored in Table-3(a) and Table-3(b).

Table-3(a): UV/Vis Spectra Data of Monomer (Solvent is DMSO/THF)

\begin{tabular}{|c|c|c|}
\hline Compound & \multicolumn{2}{|c|}{ MbC } \\
\hline$\lambda_{\max }(\mathbf{n m})$ & 262 & 338 \\
\hline $\boldsymbol{\varepsilon}(\mathrm{L} / \mathbf{m o l} . \mathrm{cm})$ & 23490 & 10224 \\
\hline
\end{tabular}

Table-3(b): UV/Vis Spectra Data of Six Polymers (Solvent is DMSO/THF)

\begin{tabular}{|c|c|c|c|c|c|c|c|c|c|c|c|c|c|c|c|c|c|c|}
\hline Compound & \multicolumn{3}{|c|}{ PMbCen } & \multicolumn{3}{|c|}{ PMbCPR } & \multicolumn{3}{c|}{ PMbCU } & \multicolumn{3}{c|}{ PMbCSc } & \multicolumn{3}{c|}{ PMbCTSc } & \multicolumn{3}{c|}{ PMbCPn } \\
\hline$\lambda_{\text {max }}(\mathbf{n m})$ & 269 & 385 & 409 & 245 & 289 & 347 & 269 & 314 & 377 & 267 & 382 & 407 & 269 & 383 & 417 & 262 & 382 & 412 \\
\hline $\mathbf{1 \%} \boldsymbol{\varepsilon}$ (L/gm.cm) & 382 & 219 & 194 & 394 & 313 & 264 & 324 & 304 & 204 & 362.4 & 162.7 & 101.3 & 377.7 & 173.0 & 116.6 & 357.4 & 152.6 & 111.5 \\
\hline
\end{tabular}


The antibacterial and antifungal studies presented promising results. All the compounds were examined against various microorganisms like S.Flexneri, M.Flavus, S.Aureus, B. Cirroflgellosus, and E.Coli for antibacterial and for antifungal activity A.Niger, A.flavus, and C.Albicans were studied. The monomer unveiled the antimicrobial activity against these microorganisms but the polymers presented enhancement in the activity, may be due to polymerization or increase in molecular weight of polymers as compared to the parent compound. The comparative analysis of antimicrobial activity of $\mathrm{MbC}$ and Schiff base polymers (Antibacterial \& Antifungal) is shown in Table-4.

Table-4: Antimicrobial Activity of MbC and Schiff base Polymers (Antibacterial \& Antifungal)

\begin{tabular}{|c|c|c|c|c|c|c|c|c|}
\hline \multirow{3}{*}{ Compound } & \multicolumn{8}{|c|}{ Zone of Inhibition(mm) $50 \mu \mathrm{g} / \mathrm{mL}^{-1}$} \\
\hline & \multicolumn{5}{|c|}{ A N T I A C T ER IAL } & \multicolumn{3}{|c|}{ A NTIFUNGAL } \\
\hline & M.FLAVUS & S.AUREUS & $\begin{array}{l}\text { B.CIRROFL- } \\
\text { GELLOSUS }\end{array}$ & S.FLEXNERI & E.COLI & C.ALBICAN & A.FLAVUS & A.NIGER \\
\hline $\mathrm{MbC}$ & - & - & ++ & - & ++ & - & + & + \\
\hline PMbCPn & +++ & ++++ & ++ & + & +++ & ++ & +++ & + \\
\hline PMbCPR & ++++ & ++++ & +++ & ++ & ++++ & ++++ & ++++ & +++ \\
\hline PMbCen & - & - & ++ & +++ & + & - & ++ & +++ \\
\hline PMbCU & ++++ & + & ++ & + & - & ++ & +++ & - \\
\hline PMbCSc & + & +++ & ++ & ++++ & - & +++ & - & - \\
\hline PMbCTSc & - & ++++ & +++ & + & - & + & ++ & ++ \\
\hline Tetracycline $^{a}$ & + & ++ & + & ++ & - & - & + & - \\
\hline Miconazole ${ }^{b}$ & - & + & ++ & + & - & - & +++ & +++ \\
\hline \multicolumn{3}{|c|}{$\begin{array}{l}\text { a STANDARD DRUG POSITIVE CONTROL } \\
\text { b STANDARD DRUG NEGATIVE CONTROL }\end{array}$} & $\begin{array}{l}- \\
+ \\
++ \\
+++ \\
++++\end{array}$ & $\begin{array}{l}=\text { INACTIVE } \\
=\text { WEAKLY AC } \\
=\text { MODERATE } \\
=\text { HIGHLY AC } \\
=\text { MOST ACTI }\end{array}$ & $\begin{array}{l}\text { IVE } \\
\text { ACTIVE } \\
\text { JE }\end{array}$ & \multicolumn{2}{|c|}{$\begin{array}{l}(5 \mathrm{~mm}) \\
(8-10 \mathrm{~mm}) \\
(11-15 \mathrm{~mm}) \\
(16-20 \mathrm{~mm}) \\
(21-24 \mathrm{~mm})\end{array}$} & \\
\hline
\end{tabular}

The antibacterial studies revealed that the parent compound MbC exhibited $(5,5,15,5,15 \mathrm{~mm})$, and the Schiff base polymers PMbCPn, PMbCPR, PMbCen, PMbCU, PMbCSc, PMbCTSc, exhibited (20,24,15,10,20mm), $(24,24,20,15,24 \mathrm{~mm}),(5,5,15,20,10 \mathrm{~mm}),(24,10,15,10,5 \mathrm{~mm}),(10,20,15,24,5 \mathrm{~mm}),(5,24,20,10,5 \mathrm{~mm})$ zones of inhibition against M.Flavus, S.Aureus, B.Cirroflgellosus, S.Flexneri, E.Coli. The monomer presented antibacterial activity however the polymers showed improved or enhanced activity against the investigated bacteria and among these polymers PMbCPR exhibited the highest antibacterial activity. The antifungal studies of the compounds under investigation revealed that the monomer showed some activity against C.Albicans, A.Flavus and A.Niger however the Schiff base polymers exhibited more activity. The monomer MbC exhibited $(5,10,10 \mathrm{~mm})$ whereas the polymers PMbCPn, PMbCPR, PMbCen, PMbCU, PMbCSc, PMbCTSc presented $(15,20,10 \mathrm{~mm}),(24,24,20 \mathrm{~mm}),(5,15,20 \mathrm{~mm}),(15,20,5 \mathrm{~mm}),(20,5,5 \mathrm{~mm})$ and $(10,15,15 \mathrm{~mm})$ compared to the stated fungi. The prepared polymers displayed antifungal activity but the parent compound displayed less activity than the polymers may be due to polymerization or lengthening of polymeric chain. The highest antifungal activity was recorded for PMbCPR.

\section{CONCLUSION}

The monomer and six Schiff base polymers were synthesized, characterized and examined via antibacterial and antifungal studies. All the synthesized Schiff base polymers exhibited less dissolution in Etoh, Meoh, $\mathrm{CH}_{3} \mathrm{COCH}_{3}, \mathrm{C}_{2} \mathrm{H}_{5} \mathrm{COC}_{2} \mathrm{H}_{5}$ whereas the parent compound expressed better solubility in organic solvents. The antimicrobial studies uncovered that the monomer was less active as compared to the polymers regarding antibacterial and antifungal studies. 


\section{ACKNOWLEDGEMENT}

The authors are thankful to Dr. M. A. Kazi Institute of Chemistry, University of Sindh, Jamshoro, Pakistan for providing research facilities at Analytical Chemistry Labs. All the microorganisms were provided by Doctor M. Kumar, Eye Hospital Pathology lab, Hyderabad, and Institute of Microbiology. The C.H.N. analysis was conducted at Carlo Elba Devon, United Kingdom. The authors are also thankful to Incharge, Softronix Science Simulation Lab (FF-21, UBIT Building), Department of Computer Science, University of Karachi, Pakistan for providing support for performing data analysis and software based simulation, and document processing of this Research paper.

\section{REFERENCES}

[1] Abdul Karim Shah, Zeenat M. Ali, Abdul Rehman Memon, A. Jabbar Laghari, Moina Akhtar Mughal, Syed Farman Ali Shah, Hussain Saleem, (2013), "Exploitation of Low Cost Coal Fly Ash Adsorbent with Coagulants for the Treatment of Industrial Complex Nature Dyes Wastewater", IJSER, International Journal of Scientific and Engineering Research, Vol. 4, Issue 9, pp.109-119.

[2] Airong Song, Stephen G. Walker, Kathlyn A. Parker, and Nicole S. Sampson, (2011), "Antibacterial Studies of Cationic Polymers with Alternating, Random, and Uniform Backbones", ACS Chemical Biology, 6(6), pp.590-599.

[3] Banerjee, Susanta, Chhaya Saxena, Pranav K. Gutch, and Dinesh C. Gupta., (1996), "Poly-Schiff bases-II. Synthesis and Characterization of Polyetherketoimines", European Polymer Journal, 32 (5), pp.661-664.

[4] Bottino, F. A., Finocchiaro, P., Libertini, E., Reale, A., \& Recca, A., (1980), "Metal Selectivity Properties of Polymeric Schiff bases", Inorganic and Nuclear Chemistry Letters, 16 (7), pp.417-421.

[5] Cazacu, M., Marcu, M., Vlad, A., Tóth, A., \& Racles, C., (2003), "Chelate Polymers. III. New Polyazomethines of 5,5'-Methylene-Bissalicylaldehyde with Siloxane Diamines and Their Divalent Metal Complexes", Journal of Polymer Science Part A: Polymer Chemistry, 41(20), pp.3169-3179.

[6] Gaurav B. Pethe, Amit R. Yaul, Jankiram B. Devhade and Ananad S. Aswar, (2010), Synthesis and Characterization of Some Chelate Polymers of Poly-Schiff base Ligand", Derpharma Chemical, Vol. 2 (3).

[7] Kumar Gutch, Pranav, Susanta Banerjee, D. C. Gupta, and D. K. Jaiswal, (2001), "Poly-Schiff bases. V. Synthesis and Characterization of Novel Soluble Fluorine-Containing Polyether Azomethines", Journal of Polymer Science Part A: Polymer Chemistry, 39, No. 3, pp.383-388.

[8] Moina Akhtar Mughal, Akhtar H. Mughal, Zeenat M. Ali, Mohammad Yar Khuhawar, Hussain Saleem, (2013), "Antimicrobial Viscometric Studies of Thermally Stable Metal based Schiff Base Polymer derived from 4, 4-Methylene Bis Furfuraldehyde", IJOART, International Journal of Advancements in Research \& Technology, Vol. 2, Issue 8, pp.6-13.

[9] Moina Akhtar Mughal, Akhtar Mughal, Zeenat M. Ali, Ghulam Zuhra Memon, Mohammad Yar Khuhawar, Hussain Saleem, (2013), "New Antimicrobial Schiff base Polymers derived from 6, 6Methylenebis (1-Napthaldehyde)", IJSER, International Journal of Scientific and Engineering Research, Vol. 4, Issue 9, pp.120-128.

[10] Naka, K., Azuma, A., \& Chujo, Y., (1998), "Metal-induced Soluble Bending Structure of Polyazomethine having a Tetradentate Ligand in the Main Chain", Macromolecular Rapid Communications, 19(10), pp.523-525.

[11] Patel, M. N., Patel, M. M., Cassidy, P. E., \& Fitch, J. W., (1986), "Synthesis of Poly-Schiff bases and Some Copper (II) and Manganese (II) Polychelates", Inorganica Chimica Acta, 118(1), pp.33-35.

[12] Samal, S., Das, R. R., Sahoo, D., \& Acharya, S., (1997), "Chelating Resins. V: Synthesis and Characterization of Chelating Resins of Formaldehyde-Condensed Phenolic Schiff bases derived from 4, 4'-Diaminodiphenyl Sulphone with Hydroxy Benzaldehydes", Polymer International, 44(1), 41-48.

[13] Sawodny, W., M. Riederer, and E. Urban, (1978), "Preparation and Thermal Stability of Polymeric Metal Chelates with Schiff bases", Inorganica Chimica Acta, 29: pp.63-68.

[14] Thomas R. Stratton, Jenna L. Rickus, and Jeffrey P. Youngblood, (2009), "In Vitro Biocompatibility Studies of Antibacterial Quaternary Polymers", Biomacromolecules, 10 (9), pp.2550-2555.

[15] Zeenat M. Ali, Abdul Jabbar Laghari, Abdul Khalique Ansari, Mohammad Yar Khuhawar, (2013), "Synthesis and Characterization of Carboxymethyl Chitosan and its Effect on Turbidity Removal of River Water", IOSR Journal of Applied Chemistry (IOSR-JAC), Vol 5, Issue 3, pp.72-79.

[16] Zeenat M. Ali, Moina Akhtar Mughal, A. Jabbar Laghari, A. K. Ansari, Hussain Saleem, (2013), "Polymeric Cellulose Derivative: Carboxymethyl-Cellulose as useful Organic Flocculant against Industrial Waste Waters", IJOART, International Journal of Advancements in Research \& Technology, Vol. 2, Issue 8, pp.14-20. 


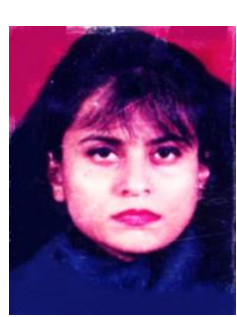

\section{AUTHORS}

Moina Akhtar Mughal is presently working as Assistant Professor at Dr. M. A. Kazi Institute of Chemistry, University of Sindh, Jamshoro, Pakistan. She has obtained her M.Sc. in Organic Chemistry in 1995, and M.Phil. in 2003 from University of Sindh, Jamshoro, Pakistan. She has completed and submitted her dissertation for the award of Ph.D. from same university and waiting for results. She has teaching experience of more than 17 years. She is the author of several research articles of national and international repute.

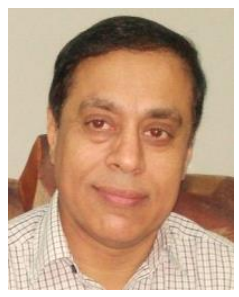

Akhtar Hussain Moghal is Professor and Director at the Institute of Physics, University of Sindh, Jamshoro, Pakistan. He was awarded Ph.D. in Experimental High Energy Physics in 1991 from Brunel University, London, UK, in the field of U.V. Photocathodes for Solid Scintillator Proportional Counter. He has completed number of research projects in the field of Gamma Radiation Detectors Prototype Photosensitive Multiwire Proportional Counter. His areas of research are novel UV-sensitive, air-stable solid photocathodes for use in solid Scintillator, Proportional counters, new Photocathodes for fast gaseous detectors, reflective UV Photocathodes for Position Sensitive Gaseous Detectors, Investigation of new Low Ionization Potential Compounds as UV-Photocathodes in vacuum and gas media.

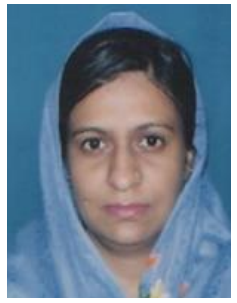

Zeenat Muhammed Ali is presently working as Assistant Professor in Chemical Engineering Department, Mehran University of Engineering \& Technology (MUET), Jamshoro, Sindh, Pakistan. She is Ph.D. Research Scholar. Her dissertation work is in final stages of submission. She has also obtained B.E. in Chemical Engineering in 1997 and M.E. in Environment Engineering in 2002 from MUET, Jamshoro. She has extensively worked in the area of Flocculation under Ph.D. studies and extracted natural flocculants from their indigenous sources and applied for water treatment for removal of turbidity, total dissolved solids and heavy metals. She has presented her work in various national and international conferences. Her work is published in various journals of repute.

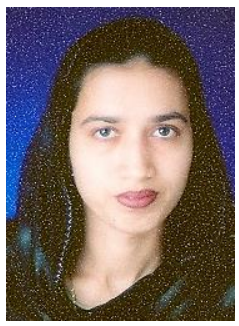

Ghulam Zuhra Memon is an Assistant Professor at Dr. M. A. Kazi Institute of Chemistry, University of Sindh, Jamshoro, Pakistan. She got Ph.D. in Analytical Chemistry from NCEAC, and M.Sc. in Physical Chemistry from University of Sindh, Jamshoro, Pakistan. She has worked as Research Associate for three years from April 2005 till Feb 2008. Thereafter she has served as Lecturer from Feb 2008 till April 2010 and Assistant Professor since April 2010 till date at Dr. M. A. Kazi Institute of Chemistry, University of Sindh, Jamshoro, Pakistan. She has over all teaching and research experience of eight years. She is an active researcher. Her research interest is in removal of toxic chemicals from water using cost effective agricultural waste material. She has also conducted research on assessment of toxic metals in soil and industrial effluents and molecularly imprinted polymers.

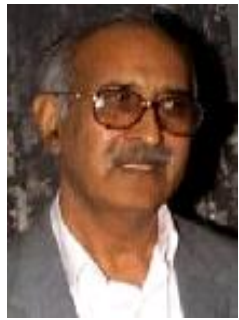

Muhammad Yar Khuhawar is Professor Emeritus, leading researcher and a versatile educator with distinguished academic carrier producing 25 Ph.D., 9 M.Phil. and 3 M.E. research scholars. He is honored with large number of National Awards, including Izaz-e-Kamal and Sitar-e-Imtiaz by President of Islamic Republic of Pakistan for achievements in scientific research. He is well known scholar having 35 years experience of teaching and research at higher education. Administrated number of fully funded research schemes and various academic tasks. National reputation for launching highly productive research workspace, in spite of meager research facilities available. He is actively committed to the field of research yielding over 283 publications in national and international journals. A large number of them are in the field of chromatography and electrophoresis for the analytical methods development for metals, non-metals and biological active compounds from wide variety of real samples; the synthesis of a number of schiff base polymers; new stationary phases for gas chromatography and sensitive liquid chromatography procedures for the determination of pesticide malathion.

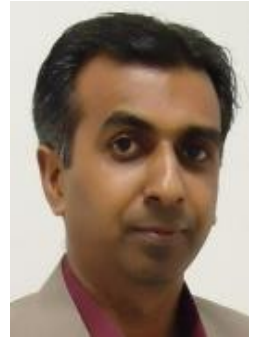

Hussain Saleem is Assistant Professor and Ph.D. Research Scholar at Department of Computer Science, University of Karachi, Pakistan. He received B.S. in Electronics Engineering from Sir Syed University of Engineering \& Technology, Karachi in 1997 and has done Masters in Computer Science from University of Karachi in 2001. He also received Diploma in Statistics from University of Karachi in 2007. He bears vast experience of more than 17 years of University Teaching, Administration and Research in various dimensions of Computer Science. Hussain is the Senior Instructor and has been associated with the Science Labs at Aga Khan Ex. Students Association Karachi since 1992. He served as Bio-Medical Engineer at Aga Khan University in 1999-2000, where he practiced to learn and handle various chemical lab tools e.g. Bio-Chemistry, Histology, Histopathology, Sample Chemistry Analysers, Radiology and MRI equipments. Hussain is the Author of more than 29 International Journal publications and co-author of about 10 Monographs. His field of interest is Software Science, System Automation, Hardware Design \& Engineering, Data Analysis, and Simulation \& Modeling. He is senior member of PEC (Pakistan Engineering Council) and member IACSIT (International Association of Computer Science \& Information Technology). 